\title{
EL CONTRATO DE TRABAJO Y SU DIFERENCIACION DE OTRAS FIGURAS CONTRACTUALES DE SERVICIOS EN EL DERECHO ESPAÑOL
}

\author{
Germán Barreiro González \\ Catedrático de Derecho del Trabajo y de la Seguridad Social \\ Universidad de León
}

Sumario*: I. Introducción. II. Contrato de ejecución de obra. III. Contrato de sociedad. IV. Cooperativas. V. Contrato de aparcería. VI. Contrato de mandato. VII. Contrato de agencia. VIII. Contrato de arrendamiento de servicios.

\section{Introducción}

La indeterminación y amplitud genérica de las notas legales que definen el contrato de trabajo obligan a una tarea de concreción constante, llevada a cabo por la doctrina, y, sobre todo, por los jueces o tribunales - «el Derecho del Trabajo se desarrolla más mediante juicios que por medio de convenios colectivos o de leyes» 1 - cuya interpretación flexible o dulcificadora del requisito de dependencia ha propiciado la expansión de las fronteras del contrato laboral y, por ende, del Derecho del Trabajo.

Viniendo tasados en la ley y especificados por la doctrina y la jurisprudencia los rasgos de la relación laboral que constituye el objeto pro-

\footnotetext{
Abreviaturas utilizadas:

AA.VV: Autores varios

AL: $\quad$ Actualidad Laboral

CC: $\quad$ Código Civil

CCDT: Cuadernos de la Cátedra de Derecho del Trabajo

CEE: $\quad$ Comunidad Económica Europea

DL: $\quad$ Documentación Laboral

ET: $\quad$ Estatuto de los Trabajadores

LAR: Ley de Arrendamientos Rústicos

REDT: $\quad$ Revista Española de Derecho del Trabajo

RL: $\quad$ Relaciones Laborales

RIT: $\quad$ Revista Internacional de Trabajo

RPS: $\quad$ Revista de Política Social

STS: $\quad$ Sentencia del Tribunal Supremo

STSJ: $\quad$ Sentencia del Tribunal Superior de Justicia

TS: $\quad$ Tribuna Social

1 GiUgNI, G.: «Il Diritto del Lavoro negli anni '80», en AA.VV.: Lavoro, legge, contratti, Bolonia, 1989, pág. 301.
} 
pio de esta rama del ordenamiento, cualquier intento de expansión del Derecho del Trabajo habrá de pasar en el futuro por la relajación o, en su caso, supresión e inexigibilidad de tales presupuestos, provocando un replanteamiento metodológico y una revisión del elemento material de la disciplina dirigido a su análisis — si dicha tendencia es considerada viable y/o conveniente - como el Derecho profesional de todas las relaciones de trabajo en sentido amplio ${ }^{2}$, en especial de todos los «contrats de dépendence»; término en el cual quedan incorporados todos aquellos contratos en los cuales tiene lugar una dependencia económica ${ }^{3}$.

En cualquier caso, las notas citadas —entendidas de forma más o menos flexible - determinan la posibilidad de diferenciar el contrato de trabajo de cualesquiera otras formas de contratación privada de servicios (constatado cómo esto es «lo que acaece en el contrato de trabajo y que no se produce en otro tipo de negocios jurídicos, para después, realizando un razonamiento abstracto, lograr establecer la naturaleza autónoma que sirva de índice de solución para calificar las situaciones fronterizas» $)^{4}$, pues «es el producto de la libre voluntad de las partes, que intercambian bienes mercantilmente iguales - trabajo y remuneración- en las condiciones que determina el libre juego del mercado» ${ }^{5}$.

Para el estudioso de la parcela social del Derecho, aparece como el modelo tipo de cooperación social inherente al proceso de producción de bienes y servicios; pero tal dato no puede ocultar cómo no todas las relaciones de cooperación cuyo objeto sea el trabajo poseen naturaleza laboral, pues «en puridad, las relaciones de trabajo, en la aceptación omnicomprensiva del término, se canalizaron... mediante diferentes instituciones»; todas ellas «receptoras de un hecho social básico y de una misma faceta de la realidad: desempeñar uno o varios cometidos por cuenta de otra persona»; en otras palabras, «trabajar por cuenta de otra persona ha sido un hecho cuya traducción jurídica se ha canalizado mediante instituciones y mecanismos diferenciados» ${ }^{6}$.

Por esta razón parece obligada la referencia — aunque sea somera- a las figuras contractuales afines al contrato de trabajo, dada la

2 Bayón Chacón, G. y Pérez Botija, E.: Manual de Derecho del Trabajo, vol. I, 12. a ed., Madrid 1978-79, pág. 23.

3 VIRASSAMY, G.J.: Les contrats de dépendance (Essai sur les activités professionnelles exercées dans une dépendance économique), París, 1986, pág. 10.

4 González-Posada Martínez, E.: El Derecho del Trabajo. Una reflexión sobre su evolución histórica, Valladolid 1996, págs. 9 y ss.

5 DurÁN LÓPEZ, F.: «El futuro del Derecho del Trabajo», REDT, núm. 78, 1996, pág. 602.

6 Alemán PÁEz, F. y CASTÁn PÉREZ-Gómez, S.: Del trabajo como hecho social al contrato de trabajo como realidad normativa: un apunte histórico romanístico, Madrid, 1997, págs. XVII y 4. 
coexistencia de éste — auténtico «Derecho de frontera» ${ }^{7}$ - con otros tipos también destinados a proporcionar cobertura a una prestación de trabajo en régimen de alteridad; habida cuenta «la coexistencia jurídica del contrato de trabajo con una serie de contratos vecinos de perfiles difusos e inconcretos a nivel causal, originadora en la realidad de una serie de zonas de calificación jurídica dudosa» ${ }^{8}$.

La delimitación de estos otros contratos, civiles o mercantiles, frente al laboral ha de ser acometida investigando sus presupuestos sustantivos y averiguando cuál sea la causa de cada uno de ellos. Tal es la tarea que se acomete a continuación.

\section{Contrato de ejecución de obra}

Por tal cabe entender aquél en virtud del cual «una de las partes se obliga a ejecutar una obra... a la otra... por un precio cierto» (art. 1544 CC); pudiendo distinguir, a su vez, dos especies: el contrato de empresa o contrata, en el cual la obra es realizada por una organización empresarial con trabajadores propios del contratista; y el contrato de arrendamiento de obra, en el cual el contratista la realiza personalmente o todo lo más auxiliado por personas de un círculo reducido y generalmente íntimo o familiar.

De las dos modalidades señaladas, sólo la segunda - por motivos obvios - plantea problemas de afinidad con el contrato de trabajo pues, en ambos, la causa es cambiaria; no coinciden, empero, ni el objeto de las prestaciones intercambiadas, ni los presupuestos sustantivos de uno y otro contrato.

En efecto, en el de trabajo el objeto es la propia actividad, «con independencia del resultado producido por la misma», mientras que la locatio conductio operis descansa «sobre la nota del resultado, independientemente de la actividad necesaria para llegar a éste»9.

Es en la clave anterior donde procede situar la diferencia entre los tipos analizados:

7 Romagnoli, U.: «Tecnocrazia e Diritto del Lavoro», Politica del Diritto, núm. 1, 1970, pág. 89.

8 Sala Franco, T. y López Mora, F.: «Contrato de trabajo», en AA.VV. (Borrajo DACRUZ, E., Dir.): Comentarios a las Leyes Laborales. El Estatuto de los Trabajadores, T. I, vol. 2. ${ }^{\circ}$, Madrid, 1994, pág. 16.

9 Alonso García, M.: Curso de Derecho del Trabajo, 9. a ed., Barcelona 1985, pág. 67, o RicCI, R.: Il lavoro privato subordinato (Il nuovo quadro di riferimento normativo. Le soluzioni giurisprudenciali), Turín, 1995, pág. 64. 
- De un lado, en el contrato de trabajo se intercambia trabajo o actividad personal por salario; el contrato de obra sirve, en cambio, para trocar un resultado previamente comprometido - la actividad pesonal del ejecutor es irrelevante para el comitente- por un precio cierto.

-De otro, el trabajo del ejecutor no reúne los caracteres constitutivos de la ajenidad y la dependencia en sentido jurídico laboral (el criterio de la dependencia, aun no siendo válido para distinguir en todo caso el arrendamiento de obra y el de servicios, presenta gran interés «en la delimitación del contrato de trabajo o laboral frente al arrendamiento de obras o servicios» ${ }^{10}$, traducido en «la imposibilidad de ejercitar los tradicionales poderes directivos y de conformación» ${ }^{11}$.

Los mayores problemas de calificación surgen cuando la remuneración del trabajador es a destajo, obligando a resolver cuándo el destajista es verdadero trabajador y cuándo empresario o contratista, habida cuenta, «en su forma más pura», acusa gran semejanza con la remuneración de una locatio conductio operis: al «no estimar la cantidad de tiempo invertido en la realización del trabajo, parece dibujar un verdadero contrato de ejecución de obra» ${ }^{12}$.

A este respecto, los criterios de la dependencia y retribución se alzan como único punto de referencia, pues:

- Por una parte, la doctrina mantiene como criterio de distinción entre el ejecutor de obra y el trabajador retribuido a destajo la incorporación de éste al círculo rector, organicista y disciplinario de la empresa, mientras aquél es el director de su propio trabajo (autoorganización).

- Por otra, en la ejecución de obra el precio o estipendio aparece siempre ajustado a un tanto alzado, como contraprestación única de un resultado final en función de su valor; en el destajo, en cambio, adquiere importancia la cantidad de trabajo, para garantizar al trabajador un salario mínimo, sin referencia a un precio global $^{13}$.

10 Sole Resina, J.: Los contratos de servicios y de ejecución de obras. Delimitación jurisprudencial y conceptual de su objeto, Madrid, 1997, págs. 23-24.

11 FANFANI, P.: «Autonomia e subordinatione: la prestazioni di lavoro nel settore sanitario», Il. Dir. Lav., núm. 1, 1988, pág. 54.

12 Bayón Chacón, G. y Pérez Botija, E.: Manual de Derecho del Trabajo, vol. I, cit., pág. 322.

13 DiéGuez Cuervo, G.: Lecciones de Derecho del Trabajo, 4. ${ }^{a}$ ed., Madrid 1995, págs. 35-40. 
La clave para distinguir ambos supuestos viene ofrecida así por la valoración en su conjunto de las notas anteriormente apuntadas, en especial la retribución, pues si el ejecutor persigue obtener un lucro especial o ganancia aleatoria, notablemente superior a la compensación normal del trabajo dependiente (salario), no podrá existir contrato de trabajo.

\section{Contrato de sociedad}

Frente a la naturaleza cambiaria del contrato de trabajo - trabajador y empresario persiguen intereses contrapuestos-, la del contrato de sociedad es asociativa, al aparecer las prestaciones dirigidas a un fin común de las partes (art. $1665 \mathrm{CC}$ : «la sociedad es un contrato por el cual dos o más personas se obligan a poner en común dinero, bienes o industria, con ánimo de partir entre sí las ganancias»); consecuencia de esta causa asociativa serán la comunidad tanto de gestión como de riesgos (positivos y negativos). Por otra parte, la igualdad entre los socios es incompatible con la subordinación jurídica o dependencia y la ajenidad (cada uno de los contratos - contrato de trabajo y contrato de sociedad- cumplen su propia función económica, las situaciones jurídicas que generan son diversas, así como su estructura y fines) $)^{14}$.

Con todo, la figura más proclive a la confusión, por ofrecer mayores semejanzas con el trabajador asalariado, es la de socio industrial o socio de trabajo cuya aportación social consiste sólamente en trabajo o industria.

Desde un punto de vista meramente dogmático, las posibilidades de confundir las figuras del socio industrial y del trabajador asalariado se cierran cuando éste queda a cubierto de los riesgos de la empresa, mientras que la condición de socio-trabajador comporta, invariablemente, tanto la participación en beneficios cuanto la asunción proporcional de las pérdidas ${ }^{15}$.

14 GreCo, P.: La società nel sistema legislativo italiano. Lineamenti generali, Turín, 1959, págs. 3 y ss.; Riva SANSEVERINO, L.: «Contrato individuale di lavoro», en AA.VV. (Borsi, B. y Pergolesi, F., Dir.): Trattato di Diritto del Lavoro, Vol. II, 3. a ed., Padua, 1958, págs. 98 y ss.; NAPOLETANO, D.: Il lavoro subordinato, Milán, 1955, pág. 164; ScoGNAmiglio, R.: Diritto del Lavoro (Parte Generale), Bari, 1972, págs. 156 y ss.; CABRERA BAZÁn, J.: «Contrato de trabajo y contrato de sociedad», RPS, núm. 54, 1962, págs. 79 y ss. ó Vergez SÁNCHEZ, M.: El socio industrial, Madrid, 1972, págs. 111 y ss.

15 Luján Alcaraz, J.: La contratación privada de servicios y el contrato de trabajo. Contribución al estudio del ámbito de aplicación subjetivo del Derecho del Trabajo, Madrid, 1994, pág. 165. 
La posibilidad de eximir al socio industrial de toda responsabilidad en las pérdidas, habilitada por el art. 1691 párrafo segundo CC, no debe ser entendida como una garantía de salario mínimo, pues en todo caso el socio, aun cuando quede exonerado de participar en desembolsos ulteriores en atención a su mayor debilidad económica, siempre arriesga, al menos, su propia aportación inicial ${ }^{16}$.

De otro lado, si bien la prestación laboral del socio industrial puede ser concebida como subordinada a los poderes directivos y disciplinarios del órgano con funciones de empresario, en realidad ésta es sólo una exigencia estructural derivada de las necesidades organizativas, dando lugar a una subordinación técnica en modo alguno equiparable a la dependencia jurídica típica del contrato de trabajo ${ }^{17}$.

En definitiva, no cabe confundir a quien «aporta su trabajo a una sociedad» con quien «presta sus trabajos en virtud de un contrato de servicios o de trabajo. Aquél lo hace en virtud de un título o estado de socio; éste lo hace por un título distinto; aquél es socio y trabajador, que es trabajador no en el sentido del Derecho del Trabajo...; éste es trabajador en este sentido» ${ }^{18}$.

\section{Cooperativas}

A los efectos que en este punto importan, el fenómeno cooperativo significa la asociación de personas físicas constituida en persona jurídica dirigida a intervenir en el mercado de bienes y servicios que recibe prestación de trabajo tanto de sujetos ajenos al ente, respecto a quienes actúa como verdadero empresario laboral (el no-socio que presta servicios laborales a la cooperativa es trabajador dependiente por cuenta ajena; sujeto, por tanto, de un contrato de trabajo regulado por el ET) ${ }^{19}$, como de los asociados, surgiendo en este caso importantes dudas sobre la naturaleza jurídica de tal prestación ${ }^{20}$.

16 Vergez SÁnchez, M.: El socio industrial, cit., págs. 111 y ss.

17 Sala Franco, T.: «Datos para una caracterización material del Derecho del Trabajo», CCDT. núm. 0, 1974, págs. 74-75.

18 Martín Blanco, J.: El contrato de trabajo, Madrid, 1957, pág. 89.

19 Montoya Melgar, A.: «Sobre el socio-trabajador de las cooperativas de trabajo asociado», en AA.VV.: Estudios de Derecho del Trabajo en memoria del profesor Gaspar Bayón Chacón, Madrid, 1980, págs. 141 y ss.; Alonso Soto, F.: «Las relaciones laborales en las cooperativas en España», REDT, núm. 20, 1984, págs. 532 y ss., o PENDAs DíAz, B., et alii: Manual de Derecho Cooperativo, Madrid, 1987, págs. 294 y ss.

20 Vicent Chulia, F.: Concentración y unión de empresas ante el Derecho español, Madrid, 1971, págs. 55 y ss.; LluIS y Navas, J.: Derecho de Cooperativas, T. II; Barcelo- 
Un examen de la Ley 27/1999, de 16 de julio, de Cooperativas, permite concluir, en principio, el carácter no laboral tanto del socio-trabajador de las Cooperativas de Trabajo Asociado, conforme establece expresamente su art. 80.1, al calificar como societaria su relación con la cooperativa, como del socio-trabajador de las Cooperativas de Explotación Comunitaria de la Tierra (pues el art. 95.2 remite a las normas referidas a las anteriores) ${ }^{21}$.

No obstante, el análisis detenido de los artículos destinados por la norma a la regulación de estos sujetos muestra, de forma clara, la imposibilidad de prescindir totalmente de institutos propios del Derecho del Trabajo, dadas las innegables analogías entre ambas relaciones (período de prueba, régimen disciplinario, jornada, descansos, fiestas, vacaciones y permisos, suspesión y excedencias...).

La Ley procede así a una «cooperativización» ${ }^{22}$, a partir de cierta asimilación del socio-trabajador al socio de la sociedad capitalista, quien puede obligarse conforme a sus estatutos a realizar aportaciones de trabajo ${ }^{23}$, sin perjuicio de reconocer, al tiempo, el fuerte paralelismo presente en la regulación de cooperativas entre el socio-trabajador y el trabajador por cuenta ajena, al gozar aquél de una posición social y económicamente equiparable ${ }^{24}$.

na, 1972, pág. 433; Vergez SÁNCheZ, M.: El Derecho de las Cooperativas y su reforma, Madrid, 1973, pág. 16; SANZ JARQUE, J.J.: Cooperación. Teoría y práctica de las sociedades cooperativas, Valencia, 1974, pág. 53; GIRON TenA, J.: Derecho de Sociedades, T. I, Madrid, 1976, pág. 96; SERrano y Soldevilla, A.D.: La cooperativa como sociedad abierta, Sevilla, 1982, pág. 21; BALleSTERO, E.: Teoría económica de la cooperativa, Madrid, 1983, pág. 145; BARRERA CEREZAL, J.J.: Gestión empresarial de la cooperativa de trabajo asociado, Madrid, 1990, págs. 249 y ss.; Fernández FernándeZ, J.: Empresa cooperativa y economía social, Barcelona, 1992, págs. 211 y ss.; CASTAÑo, J. y GonZÁLEZ, J.J.: Constitución y funcionamiento de las cooperativas, Barcelona, 1996, págs. 50-51, o Santiago Redondo, K.M.: Socio de cooperativa y relación laboral, Madrid, 1998, págs. 31 y ss.

${ }^{21}$ Idéntica conclusión cabía extraer de los arts. 118-126 y 135-138 de la Ley 3/1987, de 2 de abril, General de Cooperativas, al faltar las notas de dependencia y ajenidad.

22 VALDÉS DAL-RE, F.: «Las relaciones de trabajo en las cooperativas de trabajo asociado: algunos aspectos de su regulación jurídica en la normativa estatal y autonómica», en AA.VV.: Primeros encuentros cooperativos de la Universidad del País Vasco, Vitoria, 1986, pág. 80; contraria a la «laboralización» postulada por SANTIAGo Redondo, K.M.: Socio de cooperativa y relación laboral, cit., pág. 295.

${ }^{23}$ ECheVARría MAYo, B.: «Las relaciones asociativas y el contrato laboral», $D L$, núm. 31, 1990, pág. 50. El pacto social y la vinculación a los fines institucionales de la sociedad son los pilares sobre los que se asienta la no laboralidad, RICCI, R.: Il lavoro privato subordinato, Turín, 1995, pág. 66.

24 Ortiz Lallana, M. ${ }^{\mathrm{a}} \mathrm{C} .:$ La prestación laboral de los socios de las cooperativas de trabajo asociado, Barcelona, 1989, págs. 51 y ss. 


\section{Contrato de aparcería}

La regulación de esta materia, contenida en la Ley 83/1990, de 31 de diciembre, de Arrendamientos Rústicos vino a esclarecer la distinción - siempre compleja en la práctica - entre genuino aparcero civil [«el arrendamiento por aparcería de tierras de labor, ganados de cría o establecimientos fabriles e industriales (que), se regirá por las disposiciones relativas al contrato de sociedad y por las estipulaciones de las partes, y, en su defecto, por la costumbre de la tierra» (art. 1579 CC)] y trabajador agrícola remunerado a la parte [la Ordenanza General de Trabajo del Campo aludía al convenio «entre las empresas y sus trabajadores (para) el establecimiento del salario a la parte, consistente en asignar al trabajador una fracción determinada del producto o del importe o valor obtenido del mismo. Esta modalidad de salario se regirá por los usos de las localidades en las que se practica este sistema de remuneración, garantizándose el salario mínimo interprofesional»].

Ahora bien, aquella Ley también contempla una serie de figuras situadas a medio camino entre la aparcería civil propiamente dicha, regida por la legislación agraria, y el contrato de trabajo regulado por el ordenamiento laboral. El dato anterior ha llevado, en no pocas ocasiones, a propugnar la existencia de «encubrimiento de un genuino contrato de trabajo ${ }^{25}$ :

-En primer lugar, aparceros a quienes por pacto expreso incluido en el contrato les es de aplicación, además de la legislación arrendaticia, la legislación de trabajo y de Seguridad Social (art. 102.2), pudiendo afirmar la existencia de un verdadero contrato de trabajo ${ }^{26} \mathrm{o}$ «laboralización pactada» frente a las otras dos hipótesis de «laboralización impuesta ${ }^{27}$.

25 CABrera BAZÁN, J.: «El trabajo autónomo y el Derecho del Trabajo», en AA.VV.: Homenaje al Profesor Giménez Fernández, vol. II, Sevilla, 1967, pág. 558, o SAAVEdRA ACEVEDO, J.: «El contrato de trabajo a la parte», en AA.VV.: Catorce lecciones sobre contratos especiales de trabajo, Madrid 1965, pág. 223.

${ }^{26}$ FERnÁNDEZ Domínguez, J.J.: «Aparcería agrícola y poder de dirección en el contexto de las relaciones laborales», $A L$, núm. 21, 1991, págs. 275-276. Pese a tesis según las cuales «nos encontraríamos ante un fenómeno de extensión de la legislación laboral a supuestos o situaciones no propiamente laborales», PERALTA DE LA CÁMARA, J.L.: «Sobre la difícil aplicación de la legislación laboral a la aparcería en la Ley de Arrendamientos Rústicos», en AA.VV.: Trabajo subordinado y trabajo autónomo en la delimitación de fronteras del Derecho del Trabajo, Estudios en homenaje al Prof. Cabreza Bazán, Madrid, 1999, pág. 366.

27 Cavas Martínez, F.: Las relaciones laborales en el sector agrario, Madrid, 1995, pág. 356, o FERnÁNDEZ DomíngueZ, J.J.: «Aparcería agrícola y poder de dirección en el contexto de las relaciones laborales», cit., págs. 271-275. 
-En segundo término, aparceros que contribuyen exclusivamente con su trabajo personal (art. 108.1) o, además, realizan aportaciones de capital en pequeña cuantía — hasta el 10 por 100 (art. 108.2), supuestos en los cuales el aparcero cuenta con la garantía del salario mínimo por todo el tiempo de duración del contrato y queda, por tanto, incorporado al área de relaciones cubierta por el Derecho del Trabajo y de la Seguridad Social.

-En tercer lugar, aparceros que dedican su trabajo personal al cultivo de una tierra preparada y labrada por el cedente, por tiempo inferior a un año, garantizando al aparcero el salario mínimo así como «que el cedente se lo anticipe semanalmente a cuenta de lo que le corresponda en la liquidación final» (art. 110.1).

El carácter aparentemente laboral de las situaciones descritas ha llevado a menudo a caracterizar la aparcería como relación laboral especial $^{28}$; opción que, no obstante, cuenta con numerosos argumentos en contra, en especial aquél según el cual «las normas que la LAR contiene sobre las aparcerías... lo que precisamente no regulan, o apenas regulan, son los aspectos de la prestación laboral que pueda haber envueltos en la aparcería», dando lugar a «la paradójica situación de que estos aspectos de la supuesta relación especial se regulan por la legislación laboral común, sin que además la LAR... suministre criterio alguno para establecer las relaciones entre las dos regulaciones (supletoriedad, remisión expresa, exclusión...), otro punto que parece característico y casi ineludible para configurar una relación especial» ${ }^{29}$.

Ahora bien, lo afirmado no impide reconocer cómo el entrecruzamiento entre la legislación laboral de aplicación cuando el aparcero sólo aporta su trabajo y las normas encargadas de diseñar el régimen jurídico de la aparcería incorporan especialidades a la relación de aparcería laboral agrícola ${ }^{30}$.

28 García Abellán, J.: «El contrato de aparcería laboral agraria», REDT, núm. 20, 1984, pág. 515. Laboralidad apoyada, incluso, por solvente doctrina civilista, DíEZ-PICAZO, L. y Gullón Ballesteros, A.: Instituciones de Derecho Civil, Vol. I, Madrid, 1995, pág. 787.

${ }^{29}$ Peralta de la CÁmARA, J.L.: «Sobre la difícil aplicación de la legislación laboral a la aparcería en la Ley de Arrendamientos Rústicos», en AA.VV.: Trabajo subordinado y trabajo autonómo en la delimitación de las fronteras del Derecho del Trabajo..., cit., págs. 368 y ss.

${ }^{30}$ LuJÁn AlCARAZ, J.: La contratación privada de servicios y el contrato de trabajo..., cit., págs. 198-199. Expresiones como «aparcería laboral», «aparcería impropia», «especie laboral de aparcería»... no son extrañas a la doctrina, como muestra, por ejemplo, CAVAS MARTínEZ, F.: Las relaciones laborales en el sector agrario, cit., pág. 335. Ejemplo paradigmático viene dado por el art. 110 LAR, hipótesis clara de «mal llamada aparcería, porque en ella no se da... un reparto de productos en proporción a las respectivas aportacio- 
Aún más, ni tan siquiera cabe afirmar de forma tajante que los aparceros trabajen siempre por cuenta y bajo la dependencia del cedente $^{31}$; antes al contrario, y como ocurriera en el supuesto de los socios trabajadores, parece constituir una relación ubicada a medio camino entre el trabajo autónomo o por cuenta propia y el trabajo por cuenta ajena. Si algún sentido tiene hablar de «laboralización» respecto de estas figuras no es por referencia a la calificación técnico-jurídica del contrato (todavía de aparcería), ni del aparcero (aún trabajador autónomo, cultivador personal y directo), sino al régimen de tutela jurídica aplicable a estas situaciones parciarias, dando origen a un estatuto mixto, civil y laboral, orientado a garantizar a los aparceros de trabajo una protección cualificada en mérito a sus especiales condiciones socioprofesionales.

Por otra parte, la carencia de ajenidad en los frutos y de dependencia no es óbice para incluir a este colectivo en la esfera de actuación del ordenamiento laboral, habida cuenta la disposición final 1. ${ }^{a}$ ET prevé la existencia de formas de trabajo autónomo a las cuales cabe irradiar normas e institutos laborales («el trabajo realizado por cuenta propia no estará sometido a la legislación laboral, excepto en aquellos aspectos que por precepto legal se disponga expresamente»).

\section{Contrato de mandato}

En cuanto cauce jurídico para la sujeción a Derecho de ciertas prestaciones de servicios (art. $1709 \mathrm{CC}$ : «por el contrato de mandato se obliga una persona a prestar algún servicio o hacer alguna cosa, por cuenta o encargo de otra»), conviene proceder a la difícil tarea de distinción respecto del contrato de trabajo.

Es lugar común en la doctrina, tanto civil como laboral, negar su posible confusión, en atención al carácter naturalmente gratuito del mandato, contrario a la naturaleza típicamente onerosa del contrato de trabajo $^{32}$, pues «frente a una presunción de gratuidad, legalmente esta-

\footnotetext{
nes», Gómez LaplazA, M. ${ }^{\mathrm{a} C}$.: La aparcería agrícola en la Ley de Arrendamientos Rústicos, Madrid, 1988, pág. 237.

31 FERnÁndeZ DomíngueZ, J.J.: «Aparcería agrícola y poder de dirección en el contexto de relaciones laborales», cit., pág. 274.

32 Alvarez Alvarez, J.M.: Derecho Obrero, Madrid, 1933, pág. 36; Hernainz MárQUEZ, M.: Tratado elemental de Derecho del Trabajo, T. I, 11. a ed., Madrid, 1972, pág. 270; Pando Manjón, J.M.: Derecho Social, Madrid, 1959, pág. 30; García Oviedo, C.: Tratado elemental de Derecho Social, 2. ${ }^{\text {a }}$ ed., Sevilla, 1946, pág. 111 y PÉrez LeÑERo, J.: Teoría General del Derecho español del Trabajo, T. I, Madrid, 1952, pág. 234.
} 
blecida en el contrato de mandato, se opone la remuneración u onerosidad del contrato de trabajo como elemento esencial de éste» ${ }^{33}$.

Además, el instituto civil comprende, por esencia, la facultad de rescisión unilateral incondicionada del mandante, lo cual choca con las fortísimas limitaciones impuestas por el Derecho del Trabajo a la extinción del contrato de trabajo por voluntad del empresario.

Tampoco encaja, en fin, con el carácter intuitu personae propio de la relación laboral la posibilidad otorgada al mandatario de nombrar sustituto por el art. $1.721 \mathrm{CC}^{34}$ (a cuyo tenor, el mandatario puede nombrar sustituto si el mandante no se lo ha prohibido; pero responde de la gestión del sustituto: $\left.1 .^{\circ}\right)$ Cuando no se le dio facultad para nombrarlo. $\left.2 .^{\circ}\right)$ Cuando se le dio esta facultad, pero sin designar la persona, y el nombrado era notoriamente incapaz o insolvente. Lo hecho por el sustituto nombrado contra la prohibición del mandante será nulo).

Ahora bien, estas distinciones, rigurosamente correctas desde un punto de vista teórico, no aportan, sin embargo, adecuada solución a los problemas planteados por las siempre complejas relaciones fronterizas («se elude, por ejemplo, un pronunciamiento sobre los casos en que se concierta nominalmente un contrato de mandato en el que el mandatario está retribuido, tiene prohibido nombrar sustituto y el mandante no usa de su derecho de revocación» ${ }^{35}$ ); a lo sumo impide «identificar ambos contratos y entender que el mandato retribuido es un contrato de trabajo ${ }^{36}$, pues el criterio distintivo será, sobre todo, la ausencia de dependencia jurídica, habida cuenta la sumisión del mandatario a las instrucciones del mandante (art. 1719 CC: «en la ejecución del mandato ha de arreglarse el mandatario a las instrucciones del mandante. A falta de ellas, hará todo lo que, según la naturaleza del negocio, haría un buen padre de familia») «no tiene aquí connotaciones de subordinación, como las tiene cuando se habla de "órdenes e instrucciones" a las que se somete el trabajador dependiente, sino, por el contrario, de límites que definen el encargo objeto del mandato».

Por consiguiente, «la posición del mandatario no [es] de subordinación o dependencia, ya que la tenencia del poder, aún limitado, le hace autónomo o independiente; su "trabajo" (gestión) no es dirigido, sino que es el director de su trabajo» ${ }^{37}$. «Si una relación laboral se constitu-

\footnotetext{
33 Martín Blanco, J.: El contrato de trabajo, cit., pág. 55.

34 Menéndez Pidal, J.: Derecho Social español, T. I, Madrid, 1952, pág. 234. STS 19 mayo 1987 (Ar. 3733).

${ }_{35}$ LuJÁn AlCARAZ, J.: La contratación privada de servicios y el contrato de trabajo..., cit., pág. 112.

36 Martín Blanco, J.: El contrato de trabajo, cit., pág. 58.

37 Diéguez Cuervo, G.: Lecciones de Derecho del Trabajo, cit., págs. 38-39.
} 
ye como contrato de trabajo, aquella primitiva idea de sometimiento cuasi-servil al dominus, se ha transformado hoy, paradójicamente, en una dependencia que supone unas mayores garantías para el trabajador, por lo que se refiere a la estabilidad en el empleo y a las mejoras o "prestaciones sociales" conseguidas, frecuentemente, a través de la negociación colectiva.» ${ }^{38}$

\section{Contrato de agencia}

Este contrato de naturaleza mercantil (así lo señalan la Exposición de Motivos y el art. 3.2 de la Ley 12/1992, de 27 de mayo, sobre el Contrato de Agencia, para la incorporación al Derecho español del contenido de la Directiva 86/653/CEE, de 18 de diciembre, relativa a la coordinación de los Estados miembros en lo referente a los Agentes Comerciales Independientes) puede generar confusiones si comparado con la relación laboral especial de quienes intervienen «en operaciones mercantiles por cuenta de uno o más empresarios sin asumir el riesgo y ventura de aquéllas» [art. 2.1.f) ET] ${ }^{39}$.

Si la delimitación entre mediación mercantil no laboral y mediación laboral pero especial viene dada - como habrá ocasión de señalar- por la falta de ajenidad en el primer supuesto, la distinción entre éstas y el contrato de agencia ha partido de hacer hincapié en la nota de dependencia ${ }^{40}$ — «entendida de una forma antigua y trasnochada... que

38 Gómez-IGLEsias CASAl, A.: La influencia del Derecho Romano en las modernas relaciones de trabajo, Madrid, 1995, pág. 77.

39 BAllester PAstor, M.A.: «Notas sobre una eventual contracción del ámbito aplicativo del Derecho del Trabajo operada en las relaciones especiales de los representantes de comercio y de los altos cargos directivos», $D L$, núm. 41, 1993, págs. 107 y ss.; EscuDERO RODRÍGUEZ, R.: «Cuestiones de la incidencia laboral en las leyes no laborales», $R L$, núm. 2, 1993, págs. 81 y ss.; LÓPEZ MORA, F. V.: «La actividad de los agentes comerciales y su problemática laboral (A propósito de la Ley 12/1992, de 27 de mayo, reguladora del contrato de agencia)», TS, núm. 28, 1993, págs. 20 y ss.; Monge RECALDE, J.L.: «La Ley 12/1992, de 27 de mayo, sobre contrato de agencia y la relación laboral especial del artículo 2. f) del Estatuto de los Trabajadores», $R L$, núm. 7, 1993, págs. 101 y ss.; PEDRAJAS Moreno, A.: «Consejeros-delegados de empresas societarias y agentes comerciales independientes: dos problemáticos supuestos de exclusión de laboralidad», $A L$, núm. 23, 1993, págs. 425 y ss.; MARín CORREA, J.M.: «Los mediadores de comercio y el contrato de agencia», $A L$, núm. 77, 1995, págs. 56 y ss.; CÁmARA BotiA, A.: «Contrato de trabajo y agencia mercantil: ¿modificación de las fronteras del contrato de trabajo?», REDT, núm. 77, 1996, págs. 449 y ss., o MonTEAGUdo, M.: La remuneración del agente, Madrid, 1997, págs. 27 y ss.

40 CAStRo ArgüElles, M. ${ }^{a}$ A.: «Jurisprudencia reciente sobre contrato de trabajo», $T L$, núm. 49, 1998, pág. 9; Alonso Bravo, M.: «El contrato de agencia: ¿una vía de exclusión 
ya había sido superada por la evolución laboral» ${ }^{41}$ — y en la falta del intuitu personae, habida cuenta el agente puede asumir o no el riesgo de la operación en la que interviene, pero, en cualquier caso, goza de independencia funcional en su actuar ${ }^{42}$ y puede - eventualmente- ser una persona jurídica o un empresario en sentido laboral ${ }^{43}$. En cualquier caso, la delimitación, aun pareciendo sencilla, suele obedecer y ser efectuada «de un modo voluntarista por la jurisprudencia ${ }^{44}$.

\section{Contrato de arrendamiento de servicios}

La vinculación histórica de este contrato al de trabajo - no en vano «la independización del contrato laboral y, con éste, de aquellas instituciones que lo presuponen y sirven para desarrollarlo, se da desde el momento mismo en que es hallada la nota de subordinación o dependencia para diferenciar el contrato de trabajo del contrato de arrendamiento de servicios» ${ }^{45}$-, así como la inclusión en su momento del contrato de trabajo en el seno del CC - dentro del arrendamiento de servicios, en los arts. 1583-1587 CC, cinco «exiguos y, ya entonces, in-

de los representantes mercantiles del ámbito subjetivo de aplicación del Derecho del Trabajo?», en AA.VV. (DueÑas Herrero, L.J., Dir.): I Congreso de Castilla y León sobre Relaciones Laborales, Valladolid, 1999, pág. 393, o OTRIFIRO, S.: «I rapporti di agenzia e rappresentanza commerciale», en AA.VV.: Il Diritto del Lavoro tra flexibilità e tutela (Le trasformazioni nel setore terziario), Milán, 1992, pág. 104. «El agente es un empresario con independencia reducida y el mediador laboral un trabajador con dependencia atenuada», CÁmara Botia, A.: «Contrato de trabajo y agencia mercantil: ¿modificación de las fronteras del contrato de trabajo?», cit., pág. 472.

${ }^{41}$ LóPEZ GANDía, J.: Contrato de trabajo y figuras afines, Valencia 1999, pág. 41. En una especie de «vuelta al pasado», FERNÁNDEZ LóPEZ, M. ${ }^{\mathrm{a}} \mathrm{F} .:$ «El contrato de agencia y la representación de comercio. A vueltas con la delimitación de fronteras del Derecho del Trabajo», en AA.VV.: Trabajo subordinado y trabajo autónomo en la delimitación de fronteras del Derecho del Trabajo..., cit., págs. 166-168.

${ }^{42}$ STS 2 julio 1996 (Ar. 5631) y ORTEGA PRIETO, E.: Representantes de comercio y agentes comerciales. Su situación jurídica, mercantil o laboral, Bilbao, 1995, págs. 45 y ss.

43 Ortega Prieto, E.: «La actual calificación jurídica, mercantil o laboral, de los contratos de representación o agencia comercial», $A L$, núm. 44, 1996, págs. 859-880.

${ }_{44}$ Montoya Melgar, A.: «Sobre el trabajo dependiente como categoría delimitadora del Derecho del Trabajo» en AA.VV.: Trabajo subordinado y trabajo autónomo en la delimitación de fronteras del Derecho del Trabajo..., cit., pág. 718.

45 Alonso García, M.: Introducción al estudio del Derecho del Trabajo, Barcelona, 1958, pág. 161. Más concretamente, en el momento en que el sistema tradicional muestra su incapacidad para dar respuesta a las nuevas realidades, Borrajo DACRUZ, E.: «Presupuestos críticos para el estudio del Derecho del Trabajo», RIT, Vol. 73, núm. 6, 1954, pág. 236, o DueÑas HerRero, L.J.: «¿Transgresión o transformación en el Derecho del Trabajo?», $R L$, núm. 2, 1998, pág. 10. 
suficientes preceptos»- ${ }^{46}$, dificulta en grado sumo la tarea de deslinde pretendida $a^{47}$, al faltar «diferencia alguna de partida» ${ }^{48}$.

En todo caso, la comprensión de las relaciones entre ambas figuras contractuales, plagadas — de nuevo- de zonas grises ( «las fronteras entre el contrato de trabajo y el arrendamiento de servicios son borrosas y difíciles, resultando necesario examinar y valorar las circunstancias concurrentes en cada caso concreto» $)^{49}$, pasa por reconocer la existencia de una permanente relación dialéctica en virtud de la cual la expansión de una habrá de traer aparejada necesariamente la contracción de la otra, dando lugar a un prolongado proceso evolutivo desde la emancipación del contrato de trabajo, o «separación del Derecho del Trabajo de su originaria matriz contractual-civilista ${ }^{50}$ —alcanzada su autonomía respecto al arrendamiento de servicios-, favorecida por la vis atractiva de la relación laboral, hasta el fenómeno contrario que parece vivirse en la actualidad: la tantas veces analizada «huida del Derecho del Trabajo ${ }^{51}$.

La tendencia expansiva ${ }^{52}$ del Derecho individual del Trabajo encontró cauce apropiado en un proceso histórico de trasvase creciente de trabajadores subordinados y por cuenta ajena desde el arrendamiento civil de servicios al contrato de trabajo, evolución culminada con la laboralización última de los servidores domésticos y de los altos directi-

46 Montalvo Correa, J.: Fundamentos del Derecho del Trabajo, Madrid, 1975, pág. 251, o Molero Manglano, C.: «La configuración del contrato de trabajo», en Molero MaNGLANO, C., et alii: Estructura del contrato de trabajo (Un estudio sobre su configuración, elementos, contenido y extinción), Madrid, 1997, pág. 25.

${ }^{47}$ Sobre la tesis de equiparación de ambas figuras, un análisis y posterior crítica en Martín Blanco, J.: El contrato de trabajo, cit., págs. 17-45.

48 Molero Manglano, C.: «La configuración del contrato de trabajo», en Molero Manglano, C., et alii: Estructura del contrato de trabajo (Un estudio sobre su configuración, elementos, contenido y extinción), cit., pág. 24, citando la STSJ Andalucía/Granada 11 julio 1994 (Ar. 2917).

49 LóPEZ GANDíA, J.: Contrato de trabajo y figuras afines, cit., 1997, pág. 36.

50 Di MAJO, A.: «Incontro di studio civil-lavoristico», en AA.VV. (SANTORO PASSARELLI, G., Dir.): Diritto del Lavoro e categorie civilistiche, Turín, 1992, pág. 17.

51 Por todos, Rodríguez-PiÑERo y Bravo-Ferrer, M.: «La huída del Derecho del Trabajo», $R L$, núm. 2, 1992, págs. 1 y ss.

52 Pérez Botija, E.: La naturaleza jurídica del Derecho del Trabajo, Madrid, 1943, pág. 20; Sempere Navarro, A.V.: «Sobre el concepto de Derecho del Trabajo», REDT, núm. 26, 1986, págs. 189 y ss.; OJEDA AvilÉs, A.: «Encuadramiento profesional y ámbito del Derecho del Trabajo», RL, núm. 3, 1988, págs. 148 y ss.; Montalvo Correa, J.: Fundamentos de Derecho del Trabajo, cit., págs. 228 y 234; DE LA VILla GiL, L.E.: «La inclusión de los penados en el Derecho del Trabajo», RPS, núm. 71, 1966, pág. 193, o RuIZ Castillo, M.M.: «Delimitación subjetiva del Derecho del Trabajo. Un interrogante específico: el trabajo "parasubordinado"», $R L$, núms. 15-16, 1991, págs. 11 y ss. 
vos. Frente a tal fenómeno, el tipo contractual de arrendamiento de servicios resulta aplicable tan sólo a las prestaciones de servicios (sobre todo, profesiones liberales y ni tan siquiera respecto a éstas es claro ${ }^{53}$ ) realizadas sin las notas de ajenidad y dependencia. La cuestión sigue siendo compleja en extremo, no en vano «se toma como módulo divisor el concepto de dependencia o subordinación precisamente en el momento en que su contenido es menos preciso» ${ }^{54}$.

Llegado el Derecho del Trabajo a su madurez como disciplina, parece carecer de sentido la pretensión ilógica de adherir a su régimen cualesquiera relaciones de prestación de servicios y como tal ha sido asumida en la actualidad pues «si hasta hace unos años las modificaciones en la estructura productiva tenían como efecto la laboralización de las zonas anexas al Derecho del Trabajo, ahora, y sin perjuicio de posibles reflujos y contradicciones, lo que se aprecia es la contracción o reducción de la relación laboral típica» ${ }^{55}$.

53 Buena muestra de lo cual es la STS 17 octubre 1940 (Ar. 940), la cual reconoce la posibilidad de prestación de servicios laborales por un ingeniero. En análogo sentido, STS 21 enero 1964 (Ar. 460). En efecto, cabe hablar en propiedad de «un cierto grado de asalarización» de las profesiones liberales, LóPEZ GANDíA, J.: Contrato de trabajo y figuras afines, cit., pág. 78.

54 García Piqueras, M.: En las fronteras del Derecho del Trabajo (Arrendamientos de servicios y obras, transporte, agencias mercantiles, socios, contratos administrativos), Granada, 1999, pág. 15.

55 Dueñas HerRero, L.J.: «¿Transgresión o transformación en el Derecho del Trabajo?», cit., pág. 25. 